\title{
Perinatal mortality standards: construction and use of a health care performance indicator
}

\author{
E G KNOX, R LANCASHIRE, AND E H ARMSTRONG \\ From the Department of Social Medicine, University of Birmingham, Edgbaston, Birmingham B15 2TJ
}

SUMMARY Perinatal mortality rates are an important index of the performance of perinatal health care services, but comparisons are confounded by variations in the prior risk status of the clienteles of different districts and different maternity units. A method of allowing for these differences has been devised. It is based jointly upon the exclusion of certain classes of birth, and on indirect standardisation for birthweight and a number of modifying factors. The method is described, tested, demonstrated, and proposed for more general use.

Many perinatal deaths are determined by circumstances and events surrounding birth, and the perinatal mortality rate (PNMR) is widely regarded as a performance indicator for the perinatal health care services. ${ }^{1-5}$ However, these services have no direct control over many of the determining factors whose prevalence varies between districts and institutions. These variations sometimes offer false credit, while the indicators of poor performance can be excused or evaded.

The most powerful external factors act to determine birthweight, which strongly influences mortality. Valid comparisons of delivery care and perinatal care must first take account of birthweight differences. The major effect of birthweight variations on local PNMRs has been confirmed, the need to standardise for birthweight established, and the implications for the content of monitoring systems have been analysed. 3469

Comparisons between the smaller districts and between individual maternity units raise additional problems. Firstly, the assessments must be based on several years of data so that the results tend to be out of date. Secondly, simple birthweight standardisation can overcorrect the crude PNMR where there are substantial minorities (eg, ethnic-, parity-) with deviant birthweight distributions and different mortality/birthweight relationships. Thirdly, clienteles of individual units differ from local populations because of their admission, booking, and transfer policies. Performance indicators used in local small scale studies must therefore go beyond simple birthweight standardisation.

We aim to tackle these problems and construct more appropriate peformance indicators. The construction relies initially on prior argument but then attempts to demonstrate the validity and utility of the method so derived.

\section{Materials and methods}

The analysis is based on the $(c 250000)$ records of all the livebirths and stillbirths to residents of Birmingham in the three successive quinquennia, 1964-8, 1969-73, and 1974-78. They include records of survival, plurality, the presence or absence of a malformation, birthweight, parity, ethnic group, maternal age, duration of gestation, social class, persons per room in the household, type of labour, obstetric presentation, place of delivery, whether the delivery was booked or an emergency, and a number of other factors. The origins of the material have been described in an earlier report. ${ }^{15}$

\section{PRINCIPLES}

The problems of comparing services operating in different circumstances can be met partly through excluding certain types of case for separate and specialised consideration and through standardisation in relation to the remaining PNMR determining factors. We use both methods.

\section{Exclusions}

Multiple births The small numbers vary capriciously at maternity unit level, and the incidence is influenced by booking policies (eg, exclusion from general practitioner maternity units). Their low birthweights distort the overall birthweight distribution, and, more importantly, 
the prognostic significance of a given birthweight differs between singletons and multiple births. The simplest solution is to exclude multiple births from comparative performance indicators.

Very low birthweight Few infants weighing up to $1.0 \mathrm{~kg}$ survived the first year: $76(8 \cdot 1 \%)$ of the 933 recorded. Modern performance figures are, of course, much improved. However, variable classification as miscarriages or as stillbirths can lead to non-comparability, and WHO has recommended that, for purposes of international comparison, fetuses up to $1.0 \mathrm{~kg}$ should be excluded. We have adopted this policy here. The subsequent survival of very low birthweight babies under paediatric care is a subject for separate specialised consideration.

Fatal malformations The frequencies of different malformations vary in different places and in different ethnic groups. Malformations accounted for $26 \%$ of all perinatal deaths and $16 \%$ among Afro-Caribbeans. Exclusion may be argued on the grounds that primary prevention of most malformations is beyond the reasonable expectations of the perinatal care services, while secondary prevention through pregnancy termination deserves separate evaluation. This is consistent with the recommendations of other workers in this field.

Other possible exclusions The arbitrary limitation of PNMR to the seventh day is not nowadays entirely satisfactory. For example, the effects of low birthweight on mortality are evident throughout the whole of the first year. However, given the task accepted, we felt we had no choice but to accept the de facto standard. We examined the option of excluding births with gestations shorter than 28 weeks. We found, firstly, that the durations of short gestations were not always precisely recorded and, secondly, that the exclusion of infants $<1.0 \mathrm{~kg}$ effectively did the job. There were very few infants $>1.0 \mathrm{~kg}$ with recorded gestations below the limit. We did not, therefore, implement this additional criterion. Likewise the question of excluding macerated stillbirths was examined and declined. Early intrauterine death was effectively excluded by the $1 \mathrm{~kg}$ limit, and heavier macerated stillbirths without obvious malformations can, except for very hydropic fetuses, be treated as possible failures of perinatal care.

\section{Bases of standardisation}

Following the exclusions we were left with 248960 births; they included 3470 perinatal deaths, giving a "residual" PNMR of 13.94 per thousand births. This fell from 15.61 in the first quinquennium to 11.81 in the third. The well known effects of birthweight, of ethnic group, and of parity as major determinants of perinatal mortality were confirmed, so the first roun of standardisation was limited to these factors. We्ष opted for an indirect standardisation procedure $\frac{a}{2}$ relating the observed number of deaths to the number that would have been expected if the total populatio had conformed with a reference standard. The observed/expected $(\mathrm{O} / \mathrm{E})$ ratio provides an index of. (poor) performance. Only 4131 records $(1.6 \%)$ coul\$

Table 1 Birth weight, quinquennium and perinatal mortality rate

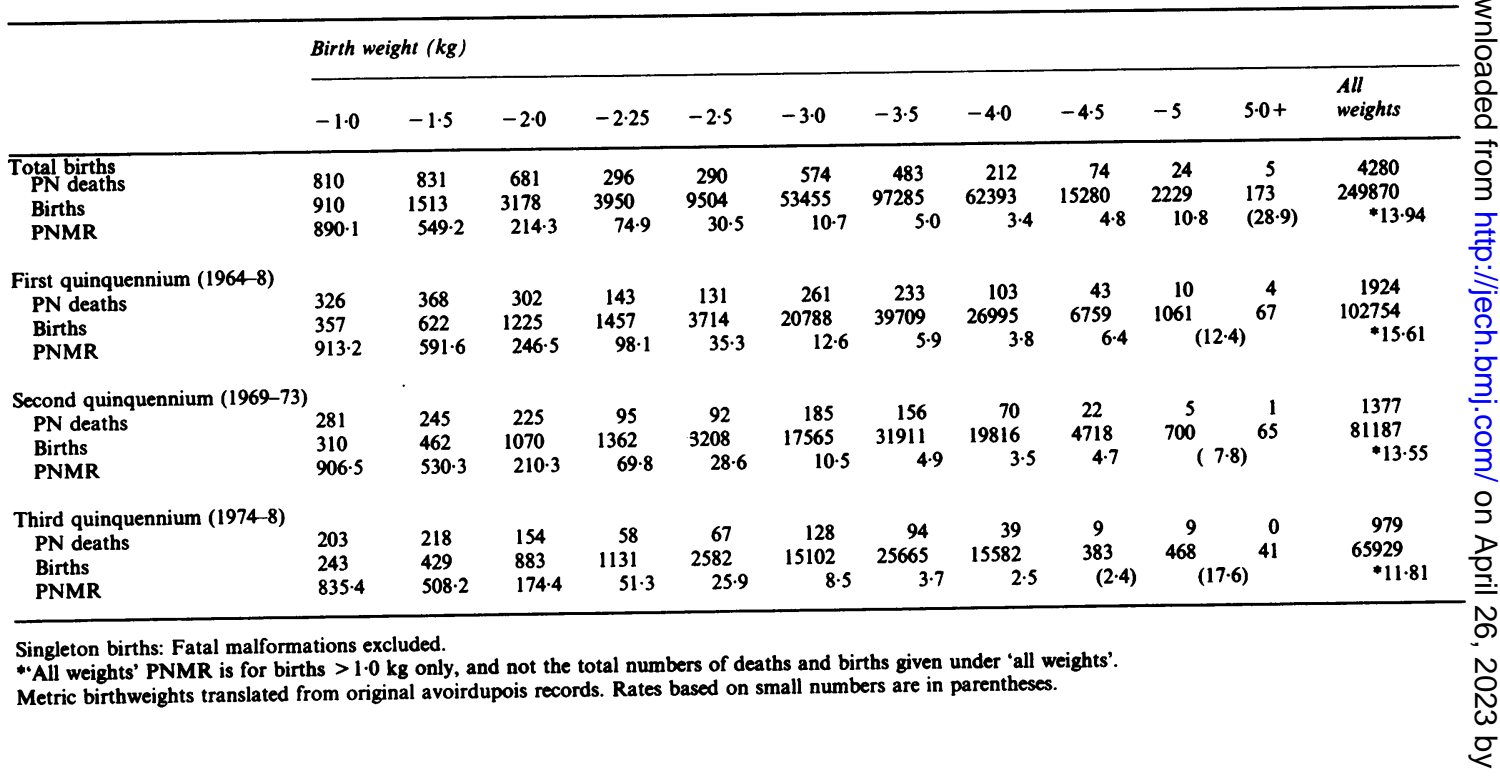


not be characterised on each of the above criteria simultaneously. Our calculations of expected mortalities were based on the remaining $98.4 \%$.

Table 1 gives distributions of total births, of perinatal deaths, and of PNMR for the three quinquennia and for the full 15-year period. Multiple births and fatal malformations have been excluded altogether. Births under $1.0 \mathrm{~kg}$ are shown in the table, although they are not included under the "all weights" PNMR calculation. The decline in PNMR was about $3 \%$ per annum and was evident in each weight group for which there were sufficient numbers. It was relatively steep in the weight band $2 \cdot 00-2 \cdot 25 \mathrm{~kg}$.

Table 2 gives distributions of births and deaths according to birthweight in four main maternal ethnic groups. They are: (1) women of West Indian or African origin, both first and second generation immigrants, hereafter classified as Afro-Caribbean (AC); (2) women with ethnic origins in India, Pakistan or Bangladesh, including a number born in Britain, East Africa or elsewhere (IP); ${ }^{3}$ women of British origin $(\mathrm{Br})$; and (4) women in "other" ethnic groups (OE), most of them, in practice, Irish. In terms of overall PNMR, the AC and IP mothers had substantially higher mortalities than $\mathrm{Br}$ mothers. The "others" were intermediate. The higher mortalities among the IP and AC groups were due to low birthweight rather than high mortalities within individual weight bands. The IP births had better survival rates in each weight band up to $3 \cdot 5 \mathrm{~kg}$ than did the $\mathrm{Br}$ births; $\mathrm{OE}$ mothers had the poorest weight specific mortalities of all.

Table 3 gives distributions of British births and deaths according to birthweight and according to the number of previous births. The overall distribution according to parity was U-shaped, being lowest in second (para 1) infants and highest in third or later infants. Once more, this is a complex effect, depending partly on different birthweight distributions at different parities, and partly on varying risks within particular birthweight bands. In all weight bands up to $3.0 \mathrm{~kg}$, first births (para 0) had the lowest mortalities. At weight bands over $3.0 \mathrm{~kg}$, second births (para 1) gave the best performances; for first births the mortality tended to increase as birthweight rose above $4.0 \mathrm{~kg}$.

A striking feature of this table is the very low mortalities enjoyed by certain groups, when multiple births and malformations have been excluded. In British births weighing between 3.5 and $4.5 \mathrm{~kg}$, the residual perinatal mortality, thus calculated, was less than 3.0 per thousand. For second and third infants, in this group, it was only 2.3 per thousand over the full 15 years. Among second infants of birthweight over 3.5 $\mathrm{kg}$ it was only 1.6 per thousand.

Social and temporal interactions The main factors associated with mortality, namely, birthweight, ethnic group, parity, and calendar year, interact in complex ways. For example, the parity distribution varied between the ethnic groups. It also changed over the 15 year period. The proportions of births in the different ethnic groups also changed during this time, and the parity distributions changed in different ways in the different ethnic groups.

The AC births comprised $9.82 \%$ of all singleton births in the quinquennium 1964-8, descending to $6.89 \%$ and $5.97 \%$ in subsequent quinquennia. The IP

Table 2 Birth weight, ethnic group, and.perinatal mortality rate

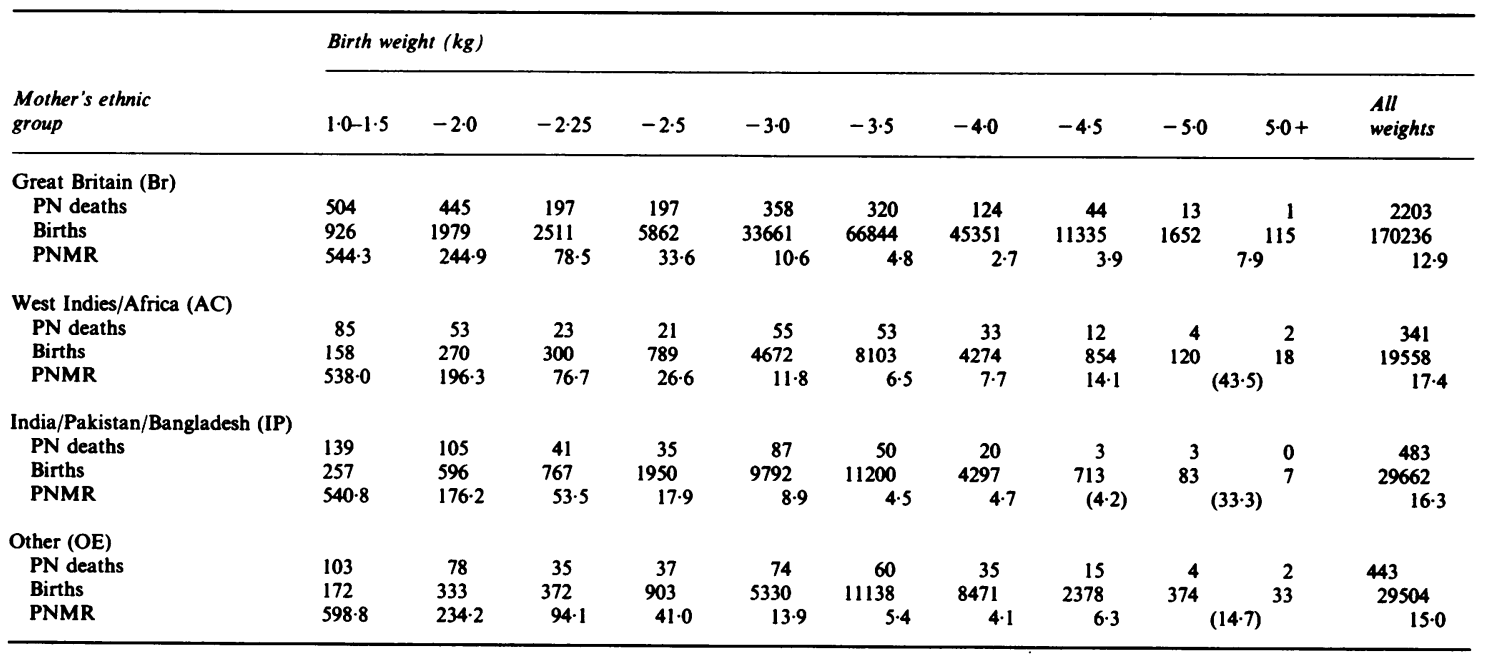

Singleton births. Births $<1.0 \mathrm{~kg}$ and fatal malformations excluded 
Table 3 Birth weight, parity, and perinatal mortality rate

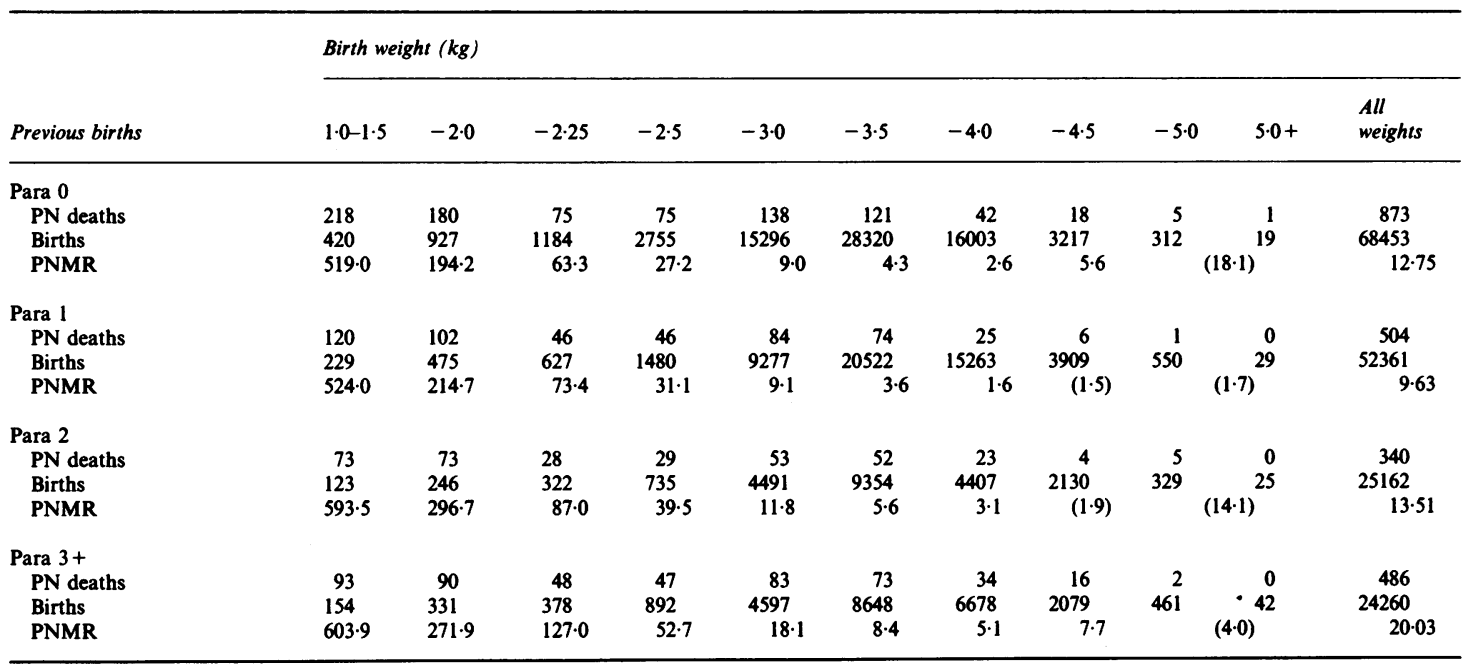

Singleton births. Births $<1.0 \mathrm{~kg}$ and fatal malformations excluded. Mothers born in GB only.

births rose from $6.17 \%$ in the first quinquennium through $13.85 \%$ in the second, to $18.49 \%$ in the last. The data in Table 3 show a para $0 /$ para $(2+)$ ratio among British births, over the full 15 years, of 1:0.72. This changed from 1:0.91 in the first quinquennium to $1: 0.50$ in the last. The AC group began with a ratio of $1: 4.70$ in the first quinquennium but converged quickly to $1: 0 \cdot 70$, close to the British ratio, in the last quinquennium. The IP births also began with a ratio very different from $\mathrm{Br}$ births, 1:2.27 but, unlike the $\mathrm{AC}$ births, this ethnic group retained a high parity distribution, and the ratio descended only to $1: 2 \cdot 02$. It is not yet certain whether this difference is likely to be maintained. The ratio may be more a function of the recentness of immigration than of ethnicity per se.

These interactive complexities, and the non-linearity of the relationships between survival on the one hand and birthweight and parity on the other, and the sensitivity of standardisation procedures to associations of these kinds, ${ }^{11}$ compromise the reliability of formal linear multivariate statistical procedures. For these reasons it was thought preferable to approach the problem of devising a predictive mortality formula based on these variables using stepwise methods.

Graphical approach Figure 1 illustrates quinquennial weight-specific "residual" PNMRs among infants of British mothers. The curves are asymmetrically U-shaped, and the temporal changes can be represented as a bodily downward movement. The improvement occurred in each weight group separately.

Figure 2 compares birthweight specific PNMRs in British births and in IP births over the full 15 year

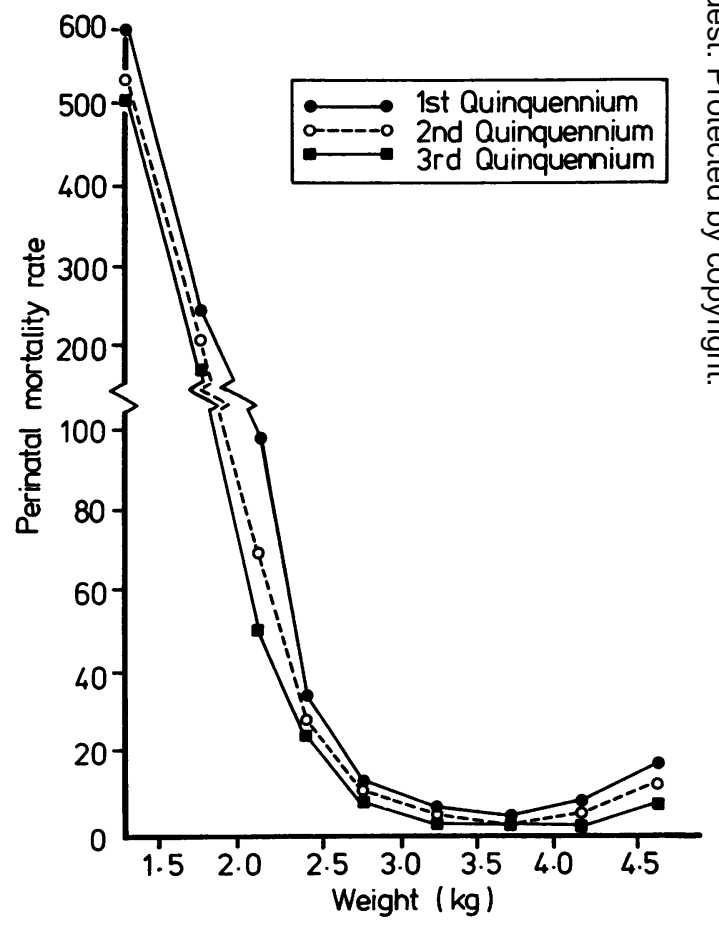

Fig 1 Birthweight and mortality:three quinquennia (GB only) (births ₹Ikg multiple:fatal malformations:excluded).

period. In contrast to the temporal changes referred to above, the difference between these curves can best be represented as a "horizontal" displacement. The IP births have weight specific mortalities corresponding 
with those appropriate to heavier European babies. The AC births (see table 2) were intermediate between the two curves shown in Fig 2, and again the relationship is best represented as a "horizontal" rather than a "vertical" shift. It should be recalled that the IP births were concentrated in the later years, when standards had improved. This partially masks the extent of the differences shown in figure 2.

Figure 3 compares births in different parity groups, for British mothers only. As with the ethnic comparisons, the curves cross in the middle range of birthweights and again suggest that the differences are most readily represented as horizontal displacements. For infants in ethnic groups or in parity groups whose mean birthweight is low, a given low birthweight has a less fatal prognosis than it does in an ethnic or parity group whose mean birthweight is relatively high.

The division of temporal, ethnic, and parity differentials into "horizontal" and "vertical" graphical displacements is to some extent arbitrary, but it allows a plausible biological interpretation which could then be transferred to different clienteles in different time periods and with different ethnic and parity structures. It also suggests a two-part basis for

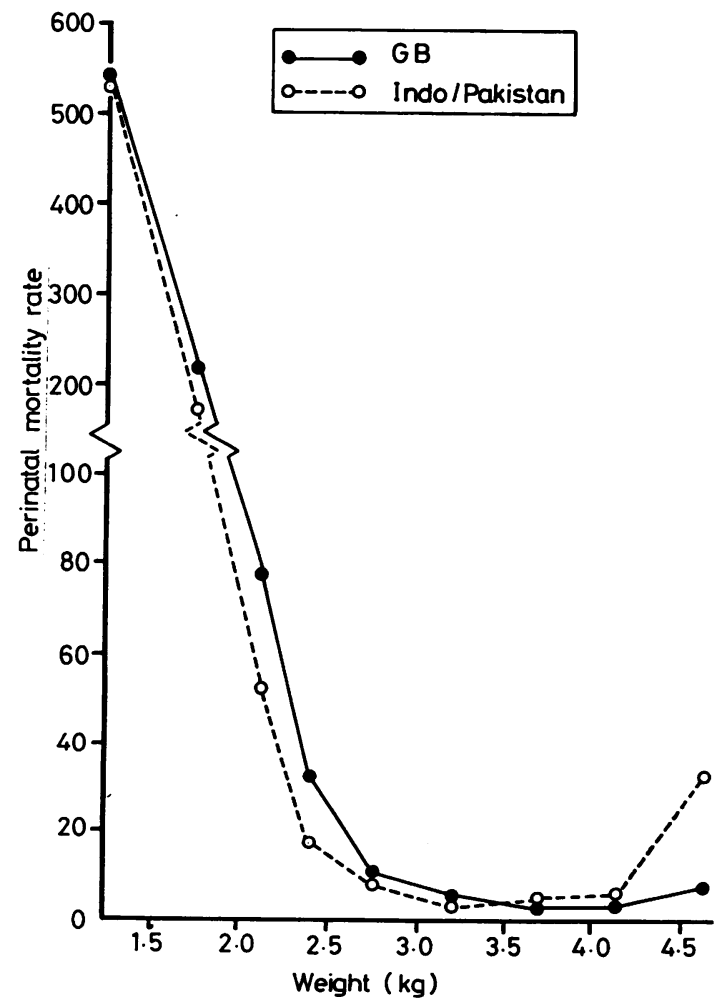

Fig 2 Birthweight and mortality:GB and Indo-Pakistan (births ₹1kg:multiple:fatal malformations:excluded).

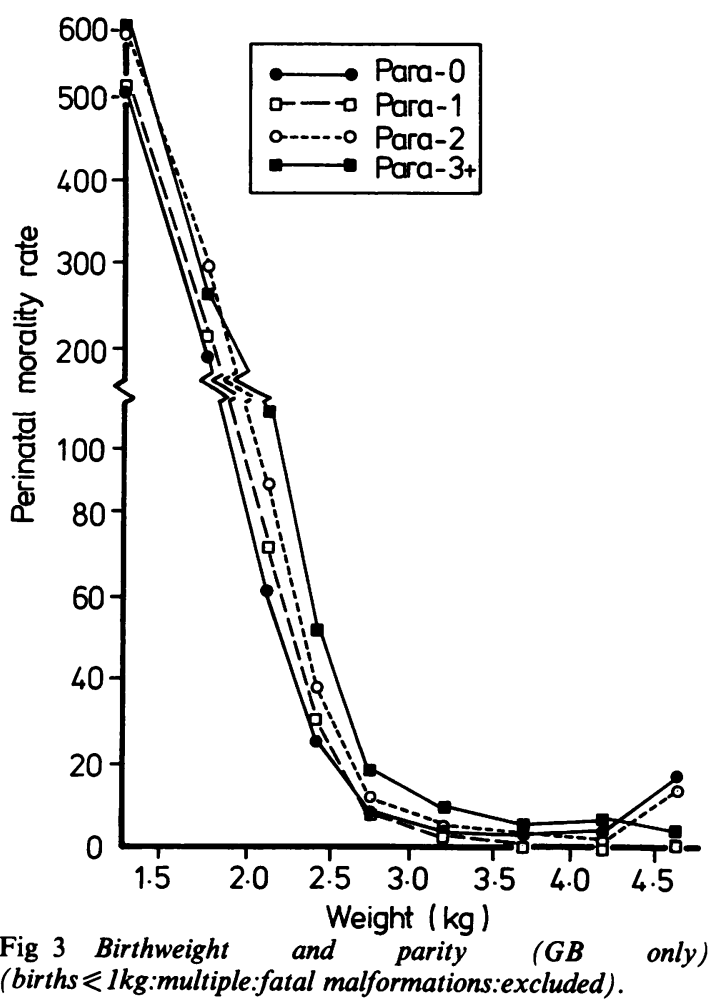

allowing for these effects within a predictive mortality formula, which could then be used as a basis for standardisation.

Mathematical representation of birthweight dependent mortality Figures 1 to 3 show that the left-most parts of the birthweight dependence graphs can be represented approximately as negative exponential curves. A high degree of flexibility, for purposes of fitting, is given by an equation of the general form:

$$
\mathrm{m}_{1}=\mathrm{e}^{-\mathrm{a}(\mathrm{x}-\mathrm{b})^{\mathrm{c}}}
$$

where $m_{1}$ is a component of perinatal mortality, $x$ is birthweight in $\mathrm{kg}$, and $a, b, c$, are constants, whose values are determined through reference to the data. The value $b$ is a "reference" birthweight, with a value less than $1.0 \mathrm{~kg}$, at which survival is supposed to be zero. The parameter $a$ controls the steepness of the curve. The parameter $c$ allows representation of a non-linear dependence of the exponent on increasing birthweight. Similar formulations have been suggested by other workers. ${ }^{16}$ The right-hand parts of the curves can be represented simply as:

$$
\mathrm{m}_{2}=\mathrm{d} \mathrm{x^{2 }}
$$

where $\mathrm{m}_{2}$ is a second component of PNMR and $d$ is a 
198

constant obtained through reference to data. Separate weight dependent predictions for different years are obtained by adding the two components $\left(m_{1}+m_{2}\right)$ and multiplying by a "year factor", $s_{y}$, to represent the temporal changes shown in fig 1 , thus:

$$
\text { PNMR' }^{\prime}=s_{y}\left(e^{-a(x-b)^{c}}+d x^{2}\right)
$$

The chief practical virtue of this inelegant expression is that it enables us to handle the "horizontal" displacements in a manner as simple as the "vertical" ones. This is achieved by adding or subtracting parity appropriate ( $p$ ) and ethnic appropriate $(q)$ supplements to the birthweight (x) before carrying out the calculation.

Calculating values for the parameters The calculations were based on iterative procedures. Values for the parameters $a, b, c$ and $d$ were based on tabulations of births to British mothers, transfer of the tabulations to a microcomputer, and iterative adjustment based on minimisation of chi-square. The year parameters, $s_{y}$ were based on a geometrical process fitted to the $a, b, c, d$ standardised mortalities of the 15 years. The factor was 1.196 in 1964 , the annual multiplier was 0.9694 , and the final 1978 value was 0.7741 . A second round of tabulations, followed by further $a, b, c, d$-adjustment was undertaken.

Parity corrections were similarly performed and were based on the British births. This permitted a further round of tabulations and subsequent iterative calculation of the necessary ethnic weight
E G Knox, $R$ Lancashire, and E H Armstrong

supplements, again using minimisation of chi square as the criterion of a "fit". Additional tabulations confirmed that the resulting procedure effectively standardised for all the variables so far taken into account but showed that maternal age was a source of additional variation. Crude PNMR exhibits a well known U-shaped variation according to maternal age at delivery. ${ }^{17}$ After standardisation for birthweight, year, parity, and ethnic group its residual relationship was approximately linear. This relationship was fairly constant in all the tested subgroups, and it could therefore be expressed as a global multiplier. The appropriate form, obtained through iteration, was:

$$
\text { maternal age factor }=(0.44+0.022 h)
$$

where $h$ is maternal age at delivery in years.

The final form of the predictive formula for calculating expected PNMR (ie, PNMR') in a mixed ethnic population was:

$$
\begin{aligned}
& \text { PNMR' }=s_{y}\left({ }^{e-2.09}(x-0.94)^{1.31}+0.00023 x^{2}\right) \\
& \times(0.44+0.022 h)
\end{aligned}
$$$$
\text { .... where } \mathrm{x}=\text { birthweight in } \mathrm{kg} \text { modified as }
$$
follows:

$\begin{array}{lllr}\text { para } 0 & +25 \mathrm{~g} ; \quad \text { para } 1 & +95 \mathrm{~g} ; \\ \text { para } 2 & -30 \mathrm{~g} ; \quad \text { para } 3 & -105 \mathrm{~g} ;\end{array}$

IP: + 90.0g; $\mathrm{Br} \& \mathrm{AC}:+0.0 \mathrm{~g} ; \mathrm{OE}:-50.0 \mathrm{~g}$;

Table 4 Comparison of observed and expected PNMR according to standardised variables: plus demonstration of postperinatal mortality (PPNMR), 1964- 78.

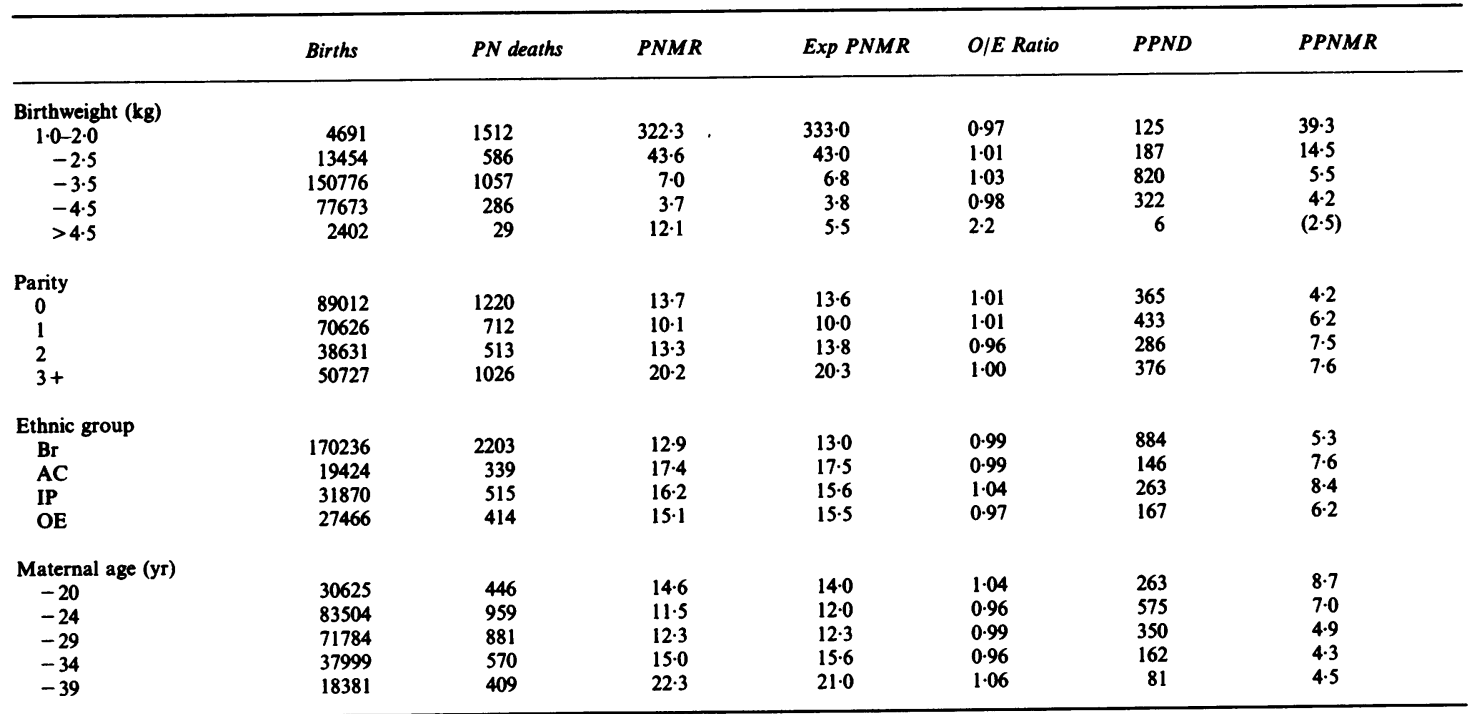

PPND = postperinatal infant deaths; $P P N M R=$ postperinatal mortality rate 
The parity corrections were not simply linear, reflecting the complex relationships between the curves in figure 3 . AC births were concentrated in the early years and at high birth ranks; allowance for these additional factors brought British births and AC births almost into line (in contrast to the uncorrected differences shown in table 2), thus obviating the need for further corrections.

\section{Additional sources of variation}

Distributions of PNMR according to birthweight, ethnic group, parity, year, and maternal age, for the full 15 year period, were compared with the expected values obtained from equation 5 . The purpose of the comparison was to see whether higher order interactions had impaired the validity of the formula or of the iteratively obtained parameter values. The main resultsare shown in table 4. (Postperinatalinfant deaths and postperinatal mortality rates are also shown.) The differences between observed and predicted mortalities are small, and the consolidated correction gives accurate predictions in all subgroups except for infants over $4.5 \mathrm{~kg}$. The sharp increase in mortality, in these weight groups, is concentrated among immigrants (see table 2); the curve-fitting, carried out originally with British births, led to an inaccuracy here. The numbers involved in this weightband are small, and this suggests that the method might be applied with some confidence to other ethnically mixed populations.

Temporal, social, and geographic variables Year by year expectations were calculated on the basis of birthweight, ethnic group, maternalage, and parity, but without the application of the "year factor". The "year unstandardised" expected PNMR', in the successive quinquennia, fell from 14.2 through 13.9 to 13.8 . This confirms that only a small proportion of the observed improvement could be due to net changes in the birthweight/ethnic/parity/maternalage structure of the clientele. The improvement is probably to be attributed to improved standards of care.

The upper part of table 5 illustrates variations of observed PNMR and expected PNMR according to social class. There is a greater than twofold differential between classes 1 and 5 in observed PNMRs. The standardised predictions follow this slope. Social classes 1 and 2 have a residual advantage, but the overall gradient across classes 1 to 5 is not sufficient to demand additional correction for the purposes of most unit comparisons or district comparisons. Only for maternity units which catered almost exclusively for social classes 1 and 2 would additional adjustments be necessary. We also conclude that the main effects of social class on PNMR in the population are mediated through birthweight variations. Records of housing conditions were incomplete (panel 2 of table 5) but reflected the social class pattern.

The Birmingham Health Area was destructured into five separate Health Authority Districts in 1982. An analysis of the perinatal mortalities in the zones corresponding to their boundaries is offered in panel 3 of table 5. Crude perinatal mortality varied from 11.3 in South District to $16 \cdot 1$ in West District. The variation is highly significant $\left(\chi^{2}{ }_{(4)}=41 \cdot 6: p>.0001\right)$. The expected values paralleled the observations, confirming that the greater part of the geographical variations is social in origin and is mediated through the birthweight/ethnic/maternal age/parity mechanism.

Table 5 Comparison of observed and expected PNMR according to social variables plus demonstration of postperinatal mortality, $1964-78$

\begin{tabular}{|c|c|c|c|c|c|c|c|}
\hline & Births & $P N$ deaths & $P N M R$ & $\operatorname{Exp} P N M R$ & $O / E$ ratio & $P P N D$ & PPNMR \\
\hline \multicolumn{8}{|l|}{ Social class } \\
\hline I & 6339 & 47 & $7 \cdot 4$ & 9.4 & 0.78 & 22 & 3.5 \\
\hline II & 20345 & 194 & 9.5 & $11 \cdot 3$ & 0.85 & 55 & 2.9 \\
\hline III & 134083 & 1841 & 13.7 & $13 \cdot 3$ & 1.03 & 676 & $5 \cdot 1$ \\
\hline IV & 44998 & 680 & $15 \cdot 1$ & 14.8 & 1.02 & 274 & $6 \cdot 2$ \\
\hline $\mathbf{V}+\mathbf{N C}$ & 42221 & 709 & 16.8 & $17 \cdot 6$ & 0.95 & 430 & 10.4 \\
\hline \multicolumn{8}{|c|}{ Persons per room } \\
\hline-1.0 & 73888 & 576 & $7 \cdot 8$ & 10.6 & - & 250 & 3.4 \\
\hline 1.0 & 85188 & 704 & $8 \cdot 3$ & 12.5 & - & 433 & $5 \cdot 1$ \\
\hline $1 \cdot 5-$ & 33285 & 304 & $9 \cdot 1$ & $14 \cdot 6$ & - & 211 & 6.4 \\
\hline $2 \cdot 0$ & 51481 & 594 & $11 \cdot 5$ & 16.0 & - & 450 & 8.8 \\
\hline NR & 5154 & 1293 & $(250 \cdot 9)$ & - & - & 116 & $(30-0)$ \\
\hline \multicolumn{8}{|l|}{ Districts* } \\
\hline Central & 42643 & 575 & $13 \cdot 5$ & $13.9 t$ & 0.97 & - & - \\
\hline North & 14963 & 204 & 13.6 & $12 \cdot 2$ & $1 \cdot 12$ & - & - \\
\hline South & 42094 & 477 & $11 \cdot 3$ & $12 \cdot 2$ & 0.93 & - & - \\
\hline East & 39862 & 519 & 13.0 & $13 \cdot 3$ & 0.98 & - & - \\
\hline West & 53622 & 864 & $16 \cdot 1$ & $15 \cdot 3$ & 1.05 & - & - \\
\hline
\end{tabular}

- Hospital booked deliveries only

† Expected values adjusted for "hospital-booked" 
Table 6 Comparison of observed and expected PNMR according to gestation period: plus demonstration of postperinatal mortality, 1964-78.

\begin{tabular}{|c|c|c|c|c|c|c|c|}
\hline Gestation period (weeks) & Births & $P N$ deaths & $P N M R$ & $\operatorname{Exp} P N M R$ & O/E ratio & PPND & PPNMR \\
\hline$<30^{*}$ & 1001 & 332 & $331 \cdot 7$ & $620 \cdot 2$ & - & 35 & $52 \cdot 3$ \\
\hline $30-$ & 694 & 283 & $407 \cdot 8$ & $340 \cdot 6$ & $1 \cdot 20$ & 16 & 38.9 \\
\hline $32-$ & 1477 & 380 & $257 \cdot 3$ & 209.8 & $1 \cdot 23$ & 22 & 20.01 \\
\hline 34 & 3138 & 361 & 115.0 & 96.0 & $1 \cdot 20$ & 48 & $17 \cdot 3$ \\
\hline $36-$ & 11214 & 490 & 43.7 & 38.8 & $1 \cdot 13$ & 109 & $10 \cdot 2$ \\
\hline $38-$ & 47401 & 498 & 10.5 & $11 \cdot 4$ & 0.92 & 258 & $5 \cdot 5$ \\
\hline $40-$ & 154033 & 632 & $4 \cdot 1$ & 6.7 & 0.61 & 776 & $5 \cdot 1$ \\
\hline $42-$ & 19489 & 138 & $7 \cdot 1$ & $6 \cdot 2$ & $1 \cdot 14$ & 97 & 5.0 \\
\hline 44 & 1588 & 19 & $11 \cdot 4$ & $7 \cdot 2$ & 1.66 & 8 & $5 \cdot 1$ \\
\hline NR & 8960 & 338 & $37 \cdot 7$ & $(19 \cdot 3)$ & - & 91 & $(10.6)$ \\
\hline
\end{tabular}

* A few births were labelled " $<28$ weeks". There was probably selection against the inclusion of stillbirths for these short gestations, which would be labelled as miscarriages. This probably accounts for the relatively favourable PNMR.

Gestation Observed and expected PNMRs are displayed in table 6 according to the estimated duration of gestation. The expected PNMR' values follow the general form of the curve described by the observed values, but there is some residual variation. There is a particularly low mortality, compared with the expected mortality, for gestations of 40-42 weeks. However, there are no systematic trends sufficient to require additional standardisation for gestation, for purposes of comparing different districts of hospitals. Postperinatal infant mortality is also displayed and shows the same relationship with gestation as it does with birthweight (see table 4).

\section{Details of delivery}

The variables considered in this section reflect clinical decisions, and factors influenced by them. To a large extent they represent questions of choice by clinicians rather than the imposed conditions under which they have to work. Standardisation in respect of these variables would not be appropriate. The main purposes of standardised comparisons, in terms of clinical risk factors, is to assist units to localise the components of a deviant overall performance.

Days and dates Table 7 compares results for infants born on different days of the week. There was a substantial excess of births on Thursdays and Fridays $\stackrel{\oplus}{\rightarrow}$ compared with other days. The lowest numbers were on Sundays and Mondays. This occurred in each quinquennium and is well documented nationally. ${ }^{18} \stackrel{\mathrm{D}}{\mathrm{O}}$ On Thursdays and Fridays PNMR was 12.81 and the $\overrightarrow{\mathbb{D}}$ expected value was $13 \cdot 48$. On Sundays and Mondays the observed value was $15 \cdot 17$, and the expected value was 14.73 .

Results for month of birth are also given in table 7. There is a suspicion of a concordant variation of observed and expected mortalities, perhaps reflecting

Table 7 Comparison of observed and expected PNMR according to different days and dates: plus demonstration of postperinatal mortality, 1964-78.

\begin{tabular}{|c|c|c|c|c|c|c|c|}
\hline & Births & $P N$ deaths & PNMR & $\operatorname{Exp} P N M R$ & $O / E$ ratio & PPND & PPNMR \\
\hline \multicolumn{8}{|c|}{ Day of week } \\
\hline Sun & 31865 & 476 & 14.9 & $15 \cdot 0$ & 0.99 & 159 & $5 \cdot 1$ \\
\hline Mon & 33443 & 515 & $15 \cdot 5$ & 14.4 & 1.07 & 219 & 6.7 \\
\hline Tues & 36423 & 515 & $14 \cdot 1$ & 13.9 & 1.01 & 203 & $5 \cdot 6$ \\
\hline Wed & 36999 & 502 & 13.6 & 13.6 & 0.99 & 215 & 5.9 \\
\hline Thurs & 37391 & 468 & $12 \cdot 5$ & $13 \cdot 5$ & 0.93 & 232 & $6 \cdot 3$ \\
\hline Fri & 37933 & 497 & $13 \cdot 1$ & 13.5 & 0.97 & 213 & $5 \cdot 7$ \\
\hline Sat & 34942 & 498 & $14 \cdot 2$ & 14.0 & 1.02 & 219 & $6 \cdot 3$ \\
\hline \multicolumn{8}{|c|}{ Month of year* } \\
\hline Jan & 21138 & 321 & $15 \cdot 2$ & $15 \cdot 1$ & 1.01 & 121 & $5 \cdot 8$ \\
\hline Feb & 19727 & 273 & 13.8 & $14 \cdot 5$ & 0.95 & 117 & 6.0 \\
\hline Mar & 22022 & 314 & $14 \cdot 3$ & 14.0 & 1.02 & 112 & $5 \cdot 2$ \\
\hline Apr & 21031 & 274 & 13.0 & 13.4 & 0.197 & 125 & 6.0 \\
\hline May & 21761 & 309 & $14 \cdot 2$ & 13.8 & 1.03 & 103 & $4 \cdot 8$ \\
\hline Jun & 21167 & 297 & $14 \cdot 0$ & $14 \cdot 3$ & 0.98 & 112 & $5 \cdot 4$ \\
\hline Jul & 21461 & 289 & 13.5 & 13.9 & 0.97 & 141 & 6.7 \\
\hline Aug & 20822 & 301 & 14.5 & 13.9 & 1.04 & 140 & 6.8 \\
\hline Sept & 20408 & 263 & 12.9 & 13.3 & 0.97 & 128 & 6.4 \\
\hline Oct & 20269 & 261 & 12.9 & 13.6 & 0.95 & 124 & 6.2 \\
\hline Nov & 19216 & 276 & 14.4 & 14.7 & 0.98 & 119 & $6 \cdot 3$ \\
\hline Dec & 19974 & 293 & $14 \cdot 7$ & 14.4 & 1.03 & 118 & 6.0 \\
\hline
\end{tabular}

* Expected values here have an additional correction to allow for that portion of the secular trend evident between months, within years: ie, 0.99741 a month. 
a minimal seasonal birthweight variation. For postneonatal deaths there was a clear excess mortality in infants born in the second half of the year. (This runs counter to the intra-annual component of the secular trend in infant mortality and cannot be explained by it.)

Obstetric variations Ninety four percent of fetal presentations were recorded as being via the vertex and $2.8 \%$ breech; the remainder consisted of other malpresentations or were not clearly recorded. Caesarean section accounted for $5.2 \%$ of deliveries, while the remainder were vaginal. Spontaneous onset of labour followed by unassisted delivery accounted for $70 \%$ of all vaginal births, while the remainder followed either a medical or surgical induction, or an instrumental delivery, or a combination of these interventions. The mortalities and expected mortalities of the main types of labour are given in table 8.

The high expected PNMR' (55.6) for breech delivery is a reflection of the relatively low birthweights of these infants. The even higher observed PNMR (84.8) is an indication of the additional dangers of this delivery mode. The observed mortality for breech delivery was 1.53 times the expected mortality; it was eight times the observed value for normal vertex presentations. Expected mortality for caesarean section, at $20 \cdot 7$, was nearly twice that for spontaneous deliveries but less than half that for breech deliveries. Caesarean sections are evidently performed on relatively immature, rather than on very immature, infants. The ratio between observed and expected PNMR was 1.05; most of the hazards of caesarean section seem to come from the associated immaturity rather than from the mode of delivery. However, the clinical exclusion of known intrauterine deaths from this mode of delivery qualifies this conclusion.

For spontaneous deliveries, the ratio between observed and expected was $0 \cdot 75$. This probably reflects the selection of high risk cases for alternative modes of labour management. Thus instrumental deliveries gave an observed/expected ratio of 1·19. Medical and surgical inductions also displayed less favourable ratios between observed and expected.

Medical inductions displayed a particularly unfavourable ratio, 2.02. A high proportion of the deaths here were stillbirths: $91 \%$ compared to $63 \%$ overall. It seems likely that a number of intrauterine deaths were diagnosed before the onset of labour, and that medical induction was then a preferred treatment once such a diagnosis had been made. The different delivery modes varied in frequency on different days of the week, and much of the day of week variation in expected and observed mortalities reflected this pattern.

Place of booking and delivery Delivery arrangements were recorded in $99.7 \%$ of all cases. Over the whole 15 years $79 \%$ of all births were booked and delivered in hospital; $16.8 \%$ were delivered at home; $0.5 \%$ were booked and delivered in nursing homes. The remainder, $3.4 \%$, were admitted to hospital as emergencies. "Booked and delivered in hospital" rose from $65.9 \%$ in the first quinquennium to $95.0 \%$ in the third. Emergency admissions were mainly transfers following a domiciliary booking. The numbers declined in parallel with the proportion delivered at home.

Analyses of the relative merits of domestic and hospital deliveries, ${ }^{19-22}$ insofar as they have concerned themselves with perinatal mortality, have in the past

Table 8 Comparison of observed and expected PNMR according to type of presentation and delivery: plus demonstration of postperinatal mortality, 1964-78.

\begin{tabular}{|c|c|c|c|c|c|c|c|}
\hline & Births & $P N$ deaths & PNMR & $\operatorname{Exp} P N M R$ & O/E ratio & $P P N D$ & PPNMR \\
\hline \multicolumn{8}{|l|}{ Presentation } \\
\hline Normal vertex & 230847 & 2420 & 10.5 & $12 \cdot 2$ & 0.86 & 1297 & 5.7 \\
\hline Abnormal vertex & 3115 & 36 & 11.6 & $11 \cdot 3$ & 1.02 & 18 & 5.8 \\
\hline Breech & 7015 & 595 & $84 \cdot 8$ & $55 \cdot 6$ & 1.53 & 53 & $8 \cdot 3$ \\
\hline \multicolumn{8}{|l|}{ Delivery mode } \\
\hline Spontaneous & 164584 & 1077 & $10 \cdot 3$ & $13 \cdot 7$ & 0.75 & 1018 & $6 \cdot 2$ \\
\hline Caesarean & 13011 & 284 & 21.8 & $20 \cdot 7$ & 1.05 & 84 & $6 \cdot 6$ \\
\hline Surgical induction * & 43583 & 516 & 11.8 & $10 \cdot 4$ & $1 \cdot 13$ & 184 & $4 \cdot 3$ \\
\hline Medical induction & 10527 & 347 & 32.9 & $16 \cdot 3$ & 2.02 & 48 & 4.7 \\
\hline Instrumental & 24671 & 352 & $14 \cdot 3$ & $12 \cdot 0$ & $1 \cdot 19$ & 105 & $4 \cdot 4$ \\
\hline \multicolumn{8}{|l|}{ Place of delivery } \\
\hline Hospital booked & 196781 & 2665 & 13.5 & 13.8 & 0.98 & 1119 & 5.8 \\
\hline All other & $52215^{* *}$ & 806 & 15.4 & $14 \cdot 6$ & 1.05 & 341 & $6 \cdot 6$ \\
\hline
\end{tabular}

* Including combined medical and surgical inductions

** Includes 41804 domiciliary deliveries and 8510 emergency hospital deliveries. The reinainder were born in nursing homes, or in unrecorded circumstances- usually outside Birmingham. 
Table 9 Performance of the maternity units (booked cases only)

\begin{tabular}{|c|c|c|c|c|c|c|c|c|c|c|c|c|}
\hline \multirow[b]{2}{*}{ Unit code } & \multicolumn{3}{|l|}{ Births* } & \multicolumn{3}{|c|}{$P N M R$} & \multicolumn{3}{|c|}{ Exp PNMR } & \multicolumn{3}{|c|}{ Ratio } \\
\hline & Q1 & Q2 & Q3 & Q1 & Q2 & Q3 & Q1 & Q2 & Q3 & Q1 & Q2 & Q3 \\
\hline $\mathbf{A}$ & 4545 & 16042 & 14212 & 15.8 & $12 \cdot 1$ & $8 \cdot 1$ & $18 \cdot 0$ & 11.9 & 9.4 & 0.88 & 1.02 & 0.86 \\
\hline B & 17647 & 15544 & 12059 & $18 \cdot 8$ & 16.4 & $14 \cdot 0$ & $18 \cdot 4$ & 14.9 & $13 \cdot 5$ & 1.02 & $1 \cdot 10$ & 1.03 \\
\hline C & 6098 & - & - & $19 \cdot 2$ & - & - & 16.8 & - & - & $1 \cdot 14$ & - & - \\
\hline D & 3706 & - & - & 16.5 & - & - & 13.7 & - & - & $1 \cdot 20$ & - & - \\
\hline $\mathrm{E}$ & 2837 & - & - & $19 \cdot 0$ & - & - & $17 \cdot 2$ & - & - & $1 \cdot 11$ & - & - \\
\hline $\mathbf{F}$ & 5015 & 3061 & 4262 & 20.7 & $13 \cdot 1$ & 10.8 & 18.3 & $14 \cdot 3$ & 10.6 & $1 \cdot 14$ & 0.91 & 1.02 \\
\hline G & 8464 & 10374 & 9149 & $12 \cdot 3$ & 11.9 & $12 \cdot 7$ & 15.7 & $14 \cdot 1$ & $12 \cdot 8$ & 0.78 & 0.84 & 0.99 \\
\hline $\mathbf{H}$ & 1117 & 1984 & 4373 & $16 \cdot 1$ & $12 \cdot 6$ & 11.9 & $12 \cdot 2$ & $9 \cdot 3$ & $10 \cdot 3$ & $1 \cdot 32$ & $1 \cdot 35$ & $1 \cdot 15$ \\
\hline I & 1356 & 1181 & 761 & $19 \cdot 2$ & $12 \cdot 7$ & 14.5 & $17 \cdot 2$ & 13.0 & 10.9 & $1 \cdot 12$ & 0.98 & $1 \cdot 33$ \\
\hline $\mathbf{J}$ & 15465 & 12127 & 7712 & $11 \cdot 2$ & $11 \cdot 6$ & $12 \cdot 1$ & $14 \cdot 5$ & 13.0 & 10.7 & 0.77 & 0.89 & $1 \cdot 12$ \\
\hline $\mathbf{K}$ & 1048 & 6221 & 9560 & $15 \cdot 3$ & $14 \cdot 3$ & 9.5 & $14 \cdot 3$ & $12 \cdot 5$ & 8.9 & 1.06 & $1 \cdot 15$ & 1.07 \\
\hline
\end{tabular}

* To Birmingham residents

$\mathrm{Q} 1=1964-68$

Q2 $=1969-73$

Q3 $=1974-78$

been fogged by two factors, namely, (a) the presumed selection for hospital delivery of cases where the general practitioner or obstetrician thought that there was a predictable risk, and (b) the subsequent denuding of high risk cases from domestic booked deliveries, through emergency transfers to hospital. These problems are partly circumvented by comparing "hospital booked and delivered" on the one hand, and the sum of domestic, nursing home, and hospital emergency admissions, on the other. The results are displayed in the last panel of table 8 .

The hospital booked deliveries gave better observed and expected mortalities. This suggests that if obstetricians identified and admitted a number of high risk women, then this was overwhelmed by socially mediated differences operating in the opposite direction. Women manipulating the system in their favour through early first attendance, or other means, were also more likely to have larger infants.

Hospital booked deliveries also showed a better performance indicator than the remainder. However, part of this was due to the unstandardised intra-year component of the improving standards, and an interaction between it and the declining proportion of home births. Our general conclusion is that, in a city like Birmingham and under the conditions then prevailing, there was little to choose between a system based entirely on hospital booking and delivery and one based on home booking followed by emergency transfer to hospital when it proved necessary.

\section{Comparing units and districts}

The main future purposes of a performance indicator are to compare individual institutions with a general standard, one type of maternity unit with another, one district with another, and one time period with another. Table 9 illustrates these applications. Home deliveries had almost disappeared by 1978 , and the data refer only to hospital booked and delivered cases. The standardisation base for this table has been adjusted to be referable to these deliveries alone.

In 1964-8 almost all deliveries to Birmingham residents took place in 11 maternity units, of which nine were inside the city boundary and two outside. The pattern changed quickly. By 1968 three units $(C, D, E)$ had closed and another $(A)$ had moved to new premises and acquired a larger and different clientele. Subsequent changes in the city boundary incorporated one of the external hospitals (K) and an additional sector of population. Two hospitals $(\mathrm{I}, \mathrm{J})$ suffered major reductions in clientele, while another $(\mathrm{H})$ saw a sharp increase.

These institutional changes were reflected in terms of performance. Hospital A, on changing premises, acquired a more favourable clientele, but its relative performance slipped. In the third quinquennium, when the unit had settled down, it became the best in the city. The units that closed in the first quinquennium displayed the second worst and third worst performances during that time. The hospitals whose loads were rapidly increased or decreased exhibited poor or irregular standards, while the four with stable institutional arrangements $(B, F, G, K)$ returned competent and steady performances.

The ratio between the worst $(\mathrm{H})$ and the best (G) performance over the full 15 years was $1.42 ; 30 \%$ of the deaths in the worst hospital would have been avoided if the standards displayed by the best had been attained. Ironically, the medical staff at hospital $G$ had at one time to defend their reputations against a libellous imputation of the hospital's poor performance. $^{23}$

These statistics are offered as examples of interpretable applications of the performance index. They cannot, of course, serve as formal validations 
Table 10 Performances of districts and maternity units

\begin{tabular}{|c|c|c|c|c|c|c|c|c|}
\hline \multirow[b]{2}{*}{ Units } & \multicolumn{5}{|c|}{ Districts } & \multirow[b]{2}{*}{$P N D$} & \multirow[b]{2}{*}{$O / E$} & \multirow[b]{2}{*}{$D S E$} \\
\hline & South & Central & East & West & North & & & \\
\hline G & 8278 & 16343 & 2499 & 735 & 119 & 343 & 0.871 & 0.964 \\
\hline A & 17309 & 8526 & 2575 & 5318 & 915 & 376 & 0.944 & 0.966 \\
\hline $\mathbf{J}$ & 1173 & 5417 & 24424 & 2462 & 1802 & 407 & 0.957 & 0.990 \\
\hline F & 9451 & 2291 & 337 & 218 & 37 & 190 & 1.055 & 0.939 \\
\hline B & 625 & 3507 & 5035 & 33091 & 2966 & 755 & 1.064 & 1.039 \\
\hline I & 378 & 1475 & 120 & 1229 & 92 & 52 & 1.099 & 1.000 \\
\hline $\mathbf{E}$ & 1594 & 712 & 194 & 248 & 87 & 54 & 1.118 & 0.958 \\
\hline $\mathbf{K}$ & 273 & 290 & 753 & 4780 & 8237 & 189 & $1 \cdot 132$ & 1.084 \\
\hline C & 38 & 130 & 160 & 5140 & 622 & 117 & $1 \cdot 162$ & 1.054 \\
\hline D & 2171 & 1108 & 61 & 340 & 26 & 61 & $1 \cdot 163$ & 0.953 \\
\hline H & 804 & 2844 & 3696 & 61 & 60 & 95 & 1.207 & 0.974 \\
\hline PND & 477 & 575 & 519 & 864 & 204 & 2639 & - & - \\
\hline O/E & 0.926 & 0.972 & 0.982 & 1.050 & $1 \cdot 122$ & - & 1.000 & - \\
\hline USE & 0.982 & 0.967 & 0.994 & 1.062 & 1.085 & - & - & 1.000 \\
\hline
\end{tabular}

Figures in central panel are births: $P N D=$ perinatal deaths

DSE, USE = district-standardised and unit-standardised performance ratios.

because there is no absolute criterion against which to set them.

Institutional/geographical interactions Table 10 distributes the hospital booked deliveries according to the maternity units (the rows) and simultaneously according to the boundaries of the currently defined health districts. The units are arranged from top to bottom in order of worsening performance $(O / E$ ratio), and the districts from left to right. Numbers of perinatal deaths are also supplied. We ask whether there are residual unexplained variations between the performances of the districts and between the performances of the units; and if both are present, whether one can be explained in terms of the other. This demands an additional level of standardisation. The final column of table 10 gives the district standardised expectation of performance based on district values alone, supposing that there were no differences between the units. These expected values cluster between +8 and -5 percentage points of the central value and do not "explain" the much wider inter-unit performance range . The final row of table 10 gives the unit standardised expectation based on unit values alone, supposing that there were no differences between the districts. Here, by contrast, the gradient of expectations matches the gradient of observations.

The statistical significance of the unit variations and their independence from district variations was established through analysis of variance. The variation between districts was not significant, confirming analyses associated with table 5 . Our conclusions are that the units exhibited a varied performance which could not be explained either in terms of the variables used for constructing the performance index or in terms of their geographical locations; whereas, by contrast, district variations were almost entirely explained in terms of the client factors already used, and in terms of the varying qualities of the hospitals that served them.

\section{Discussion}

Previous studies of large scale geographical variations of PNMR in the United Kingdom emphasised the determining importance of parallel birthweight variations. ${ }^{35}$ The present study confirms this on a more local scale; birthweight variations largely explain the PNMR differences between social classes and districts. However, performance can be predicted more precisely by excluding certain classes of birth from the assessment, and by taking additional account of calendar year, ethnicity, parity, and maternal age. The calendar year and mother's age influenced survival across all the weight groups, while ethnicity and parity variations resemble a birthweight supplement or decrement.

These relationships suggested the algebraic format of an expression for calculating the "expected" PNMR' of a district or maternity unit and then constructing a performance index based on the ratio between the observed and expected deaths. A predictor of this kind is entirely different from one which might be used by a clinician in predicting risks to an individual. Many indices of this last kind have been constructed in the past and sometimes used to calculate the expectations against which the performance of a unit might be assessed. They are, however, inefficient, failing to make use of birthweight, and they are strictly not valid for this purpose. They incorporate a clinical activity (ie, a prior risk assessment), which is itself a component of the performance that is to be measured.

Our own method could be challenged on the grounds that satisfactory birthweight might be regarded as an outcome, rather than an operational contingency, of the care provided. If a maternity unit reduced maternal usage of cigarettes, and consequently increased the birthweights of its infants, it would receive no "credit" under the terms of this performance indicator. The performance indicator must therefore be applied only to services which are strictly perinatal,and not those concerned with earlier antenatal care.

It has been shown ${ }^{11} 14$ that where a population can be segregated into strata in which the relationships between mortality and birthweight differ, then standardisation procedures (whether indirect, as in the present case, or direct) can introduce bias. The over-compensatory effects of birthweight 
standardisation in administrative areas with large ethnic minorities ${ }^{910}$ are a case in point. It has sometimes been argued that difficulties of these kinds invalidate the "standardisation" approach to measuring performance. We defend the approach because: (i) the weight correction procedures for ethnic group and parity, and the exclusion of multiple births from the calculation, greatly reduce the ill effects of such heterogeneity; (ii) any residual bias is probably the least bias that can be obtained, and is certainly much less than that associated with unstandardised mortalities; and (iii) pragmatically, the method does indeed seem to differentiate good performance from relatively poor performance in a manner that is interpretable, and with a consistency and penetration which could not be achieved using crude PNMR.

Equation [5] is not directly transferable. It refers to the population of Birmingham in the period 1964-78 and in strict terms is only applicable to performances measured within that context. However, the use of a general model with a biological and social interpretation, as opposed to a simple multivariate formula, permits its wider use. The parameters should preferably be recalculated in new contexts, although the birthweight supplements for ethnicity and parity, and the exponent parameters of the mortality/birthweight curve, could probably be more widely used with little risk of serious error. However, the "year factor" is not directly transferable. Regular recalculation is mandatory on a national or regional basis if we are to compare districts and units and follow their positions within a "league table". It is also necessary that records of perinatal deaths should in future contain all the information necessary for appropriate exclusions, and that the records of survivors should contain all the information for calculating the expected numbers of deaths.

\section{References}

${ }^{1}$ Black N, Macfarlane A. Methodological kit: Monitoring perinatal mortality statistics in a health district. Community Med 1982 4: 25-33.
2 Alberman E. Prospects for better perinatal health. Lancet 1980 1: 189-92.

${ }^{3}$ Mallett R, Knox E G. Standardized perinatal mortality ratios: technique, utility and interpretation. Community Med. 1979 1: 6-13.

${ }^{4}$ Knox E G, Marshall T, Kane S, Green A, Mallett R. Social and health care determinants of area variations in perinatal mortality. Community Med. 1980 2: 282-90.

${ }^{5}$ Knox E G, Mallett R. Perinatal mortality: effectiveness selective interventions. Lancet 1979 2: 734-5.

${ }^{6}$ Chalmer I, Adelstein A M. Adjusted perinatal mortality rates in administrative areas of England and Wales. Health Trends 1978 10: 24-9.

${ }^{7}$ Chalmers I, Adelstein A M. Improving the quality of perinatal statistics. Lancet (1981) 2: 640 .

8 Cooper S A, Harris A S, Holmes B S , Richards G. Perinatal mortality. Lancet 1979 2:1305.

${ }^{9}$ Marshall T, Mallett $R$. Variation in perinatal mortality by Region and Area. Hosp Ser Rev 1980 76: 58-61.

${ }^{10}$ Marshall T, Mallett R. The influence of racial mix on comparisons of perinatal mortality rate between area health authorities. Int J Epidemiol. (1980 9: 255-63.

11 Wilcox A J, Russell I T. Perinatal mortality. Why standardize for birthweight? Paper read to the Society for Social Medicine. 1982. In press.

12 Kleinman J C. Indirect standardization of neonatal mortality for birth weight. Int J Epidemiol 1982 11: 146-54.

${ }^{13}$ Editorial. Which birth weight standards? Br Med J 1978 4: 1384.

14 Rooth G. Low birthweight revised. Lancet 1981 1: 639-41.

15 Charles E. Statistical utilization of maternity and child welfare records. Br J Soc Med 1951 5: 41-61.

${ }^{16}$ Wilcox A J, Russell I T. Birthweight and perinatal mortality: On weight-specific mortality. Int $J$ Epidemiol 1983 12: 319-25.

17 Adelstein A M, Macdonald D I M, Weatherall J A. Perinatal and infant mortality: biological factors 1975-77. Studies on Medical and Population Subjects 1980 No. 41. HMSO.

18 Macfarlane A. Variations in numbers of births and perinatal mortality by day of the week in England and Wales. Br Med J 2: 1670-3.

19 Tew M. The safest place of birth. Lancet 1979 1: 1388-90.

20 Tew M. Obstetric hospitals and general-practitioner maternity units- the statistical record. J R Coll Gen Pract 1977 27: 689-94.

21 Tew M. The case against hospital deliveries: the statistical evidence. In: Kitzinger S, Davis J, eds. The place of birth Oxford University Press 1978 55-65.

22 Tew M. Home versus hospital confinement: the statistics. Update 1979 18: 1317-22.

${ }^{23}$ Legal correspondent. Libel by cartoon. Br Med J 1982 285: 1664. 